\title{
Cyber Delinquency: Issues And Challenges Under Indian Legal System
}

\author{
Astha Srivastava, Shivangi Sinha
}

\begin{abstract}
Children are the shoulders which carry a nation to the future. It is important for a nation to develop that its youth are on the right tracks. But even if sometime a child shows a behavior which is uncalled for a society and delinquent in nature that does not means that he is no longer fit to be a part of the society. Children are a fragile mind and can be put on the right course of development through proper guidance. This paper aims at discussing the reason why minors are more and more involving themselves into committing offences with the aid of technology. Technology which is aimed at their development is in some case proving to be there enemy. The paper further focuses on various types of cyber crimes and how our legal system can control cyber crimes by minors.
\end{abstract}

Index terms- Cybercrime, Juvenile, cyber pornography, cyber suicide, digital piracy

\section{INTRODUCTION}

An act of a person which has wrongful effect on the society at large is a crime. This Characteristic of any wrongful act is what makes it a crime. It is presumed to have been committed against the society and therefore the society initiates proceeding against the wrongdoer. Whenever any wrongful act is committed with the aid of information and communication technology such crimes are known as cybercrimes. We as a society are becoming a technology driven society with new technologies being invented day by day. Every individual is now a stakeholder in this technology driven world. Our communications are becoming faster and cheaper, our financial transactions are becoming easier, our businesses are flourishing because of new software to speed up the process. With the advent of new technologies like artificial intelligence this whole structure is upgrading to the next level.

As we are growing into an E-world we are becoming more vulnerable towards various threats which come hand in hand with technological advancements. This threat which is associated with technological development is the reason behind the development of the concept of cybercrimes. The term cybercrime has nowhere been defined under Indian law but the INFORMATION TECHNOLOGY ACT, 2000 and information technology amendment act of 2008 deals with various types of cybercrimes and rules governing them.

When it comes to access to the technology and computers there is no difference between a child and an adult. In today's world children are also a major stakeholder of this

Revised Manuscript Received on April 19, 2019.

Astha Srivastava, Assistant Professor, Bharati Vidyapeeth (Deemed to be University), New Law College, Pune, Maharashtra, India.(Email: srivasthavastha9@gmail.com)

Shivangi Sinha, Assistant Professor, Bharati Vidyapeeth (Deemed to be University), New Law College, Pune, Maharashtra, India.(Email: shivangisahay8@gmail.com) technology driven world and it affects their day to day life in the same way as an adult. The peer pressure which is engulfing the society these days is resulting into increased visibility on social media platforms. These social media platforms don't differentiate between child and adult and therefore children also have access to all the information to which an adult has access. All this exposure if exercised within a permissible limit gives the children an opportunity to groom hand in hand with the fast pace society. But sometimes technology is not used to benefit from it but rather is utilized for some wrong motives and to harm other person. Cyber fraud and various other cyber-crimes are committed by juvenile who are using technology for their wrongful gains. Various types of cyber-crimes committed by juvenile are cyber frauds, cyber bullying, cyber stalking, identity theft, drug trafficking, digital piracy, cyber suicides, cyber theft, illegal; hacking etc. apart from these known cybercrimes daily new crimes are committed by means of technology. The condition is worsening day by day but what is more worrisome is that these children who are committing these acts are not even aware in most of the situations that what they are doing thinking to be casual affair is a crime which carry with itself severe sanctions.

If we evaluate the reason behind increasing cyber delinquents in India the main amongst them would be unawareness of outcome of trivial acts. Children who are unable to apprehend there steps on the basis of cost benefit analysis usually fall into the trap of committing cybercrime. They are driven by short lived happiness and entertainment and are unaware as to when they start to transgress on the boundary of others rights and end up committing a cybercrime. A very common example of this is Digital Piracy. Children usually download movies, songs etc. from untrustworthy site without even knowing that what they are doing is infringement of copyright of the owner. Sending hateful mails to classmates, downloading photos of other people from social networking sites and depicting it in funny way these all are cybercrimes.

\section{METHODOLOGY}

\section{Cyber Delinquency In India-}

Cybercrimes have been increasing in numbers year by year. In the same way cyber delinquency has also been increasing day by day. If we focus on the data as published by the national crime record bureau there is an increasing pattern in cyber delinquency. The reason behind this is many fold but the issue is still unresolved. Internet exposure 
is increasing day by day and with it increases the vulnerability of our kids. Recently new forms of cybercrimes have been committed by juvenile in India.

\section{Cyber suicides-}

Suicide is one of the major causes of death amongst the youth in the whole world. The term cyber suicide is a new term coined to cover those cases of suicide which have been abetted using technology in one way or the other. People record there suicide or display their suicide live using internet. Recently a Blue Whale challenge named phenomena started in Social networking sites. This game consisted several tasks which the player has to complete. The final task in this game was to commit suicide. Many unrelated suicides happened which were influenced by this game. This game was created by a 21 year old Russian who admitted that he created this game so that children could commit suicide and the society is cleaned.

\section{Cyber Pornography-}

Display, Publish, Distribute, Create, import obscene or pornographic material through online medium. Technology is for the aid and advancement of human kind. It's a necessity of today generations. But kids these usually make use of technology for committing acts which are prohibited. One of such act is cyber pornography. Cyber pornography is not specifically described as a cyber crime under IT act, 2000 but section 67 of the act provides punishment and fine for publishing, transmitting or causing to be published or transmitted any data which is obscene in nature.

Children are the building blocks of the nation. There all round development is quintessential for the development of the nation. But sometime children tend to do acts which are contrary to the culpable interest of the society. The primary responsibility of the state is to focus on these children who are termed as juvenile in conflict with law and not juvenile delinquents under the JUVINILE JUSTICE (CARE AND PROTECTION OF CHILDREN) ACT OF 2015. Under Indian legal system, Juvenile in conflict with law are reformed and not punished for their wrongful acts. The act is aimed at reforming the delinquent so that a minor who committed a wrongful act without being capable of understanding the nature of the act is not converted into a hardcore criminal.

When it comes to cyber crime committed by minor the $\mathrm{JJ}$ ACT of 2015 and it act of 2000 will both be applicable together. But juvenile cyber delinquency is a grey area in these laws no specific provision is there providing for cyber crimes by minor.

\section{FINDINGS}

\section{Reforms To Prevent Juvenile Cyber Delinquency}

Cyber crime is a growing threat to the all round development of the society. When cyber crime is committed by a minor it becomes an impediment in the growth of our youth and also poses threat to future of the state. Therefore it becomes a primary task to focus and curb cyber crimes being committed by minors. Various reforms are needed in our current legal system to prevent and curb juvenile cyber delinquency. Few of those are as follows-

Need for amendment in present legal system-
The present legal system needs changes in order to prevent and control commission of cyber crimes. In case minor's turn into cyber criminals then they should not be treated in the same as a minor who commits any other crime. For this it is important that our legislature understands the peculiar nature of cyber crimes. Some of such crimes are committed out of unawareness and inquisitiveness without knowing the consequences and some other cyber crimes are pre planned and involve lot of preparation. Therefore cyber criminals should be treated as a separate category.

\section{Widespread awareness-}

There is lack in knowledge when it comes to cyber related offences. Our children are not aware about intellectual property rights, privacy rights, and sensitive information and therefore they take these things casually and end up committing cyber crimes. Hence it is necessary that they are made aware of the proper use of technology and what results its misuse would entail.

\section{RESULT AND DISCUSSIONS}

The term "cyber" the use of which became universal by the late 1980s find its origin several decades earlier when Nobert Wiener coined the term 'cybernetics in 1948 and described the same as the study of the interrelation of machine with society. The rapid development of Internet and computer technology globally has led to the new forms of transnational crime which may affect the country across the globe. Thus there is a need for awareness and enactment of necessary legislation across the territorial boundaries for the prevention of computer related crimes. However, none of the legislation when taken into consideration specifically talks about the involvement of juvenile in such crimes their cause and remedies. For instance, In India till date there exist no treaty with any other countries to extradite any cyber crime offenders. In India, most of the cyber crimes are listed under the Information Technology Act, (IT Act, 2000), which was later amended in the year 2008. The other governing statutes are the Indian Penal Code 1860, The Evidence Act 1872, The Negotiable Instrument Act1881 etc. However, none of the above stated legislations explicitly talks about the crime committed by the juvenile in the virtual world. If we talk about the status of United States of America, so apart from having their domestic legislations such as The Wire Frauds Statute, The Computer Fraud and Abuse Act 1984 (CFAA) etc. The international perceptive of cybercrimes are covered under treaties like Conventions made against the transnational organized crime in the year 2000, Conventions which looks after the rights of the child in the year 1989, there was also an optional protocol made which mentioned some specific rights of the child related to cyber crime in the year 2001.

At the same time, the Council of Europe also creates law which controls the British Criminal Justice system. It interconnects all the countries having same background and is open to signatories for all other countries. They focused 
more on the Conventions which contain cybercrimes related to xenophobic nature committed through computer system (2003) and conventions on the protection of children against sexual exploitation and sexual abuse (2007).Some of the above mentioned treaties expressly prohibit child pornography, distribution of such materials etc but still we can infer firstly, there are "legal framework", but yet to have an international cooperation worldwide and secondly, juvenile delinquency under cyber space is a started but unfinished picture far and wide.

\section{CONCLUSION}

There can be no single reason for the causes of cyber delinquency. The causes of cyber delinquency can be wide ranging from social to personal factors. For instance, the social factors can include broken homes, poverty, and lack of parental affection or security. Lack of family ties and broken relationship led to the steep rate of growth of the cyber delinquency. The personal or individual factors in relation to juvenile delinquency can be peer or community background, emotional issues etc. Therefore, we can see that the reasons considering which the juvenile can commit any cyber crime cannot be put into any water tight container and can be analyzed.

Other factors which can be taken into consideration are lack of knowledge i.e. the juveniles are not aware of the fact that their activities can led to any sort of cybercrime, this can also happen because these days it is very easy to access any computer system from unauthorized access. So unawareness can be considered as one of the factor for the same. The computers run on operating system and are programmed from millions of bits, bytes and codes and the juvenile minds are at imperfect stage, so they can do mistakes anytime, the gaps created by them can also led to the cybercrimes. Another factor which can be taken into consideration for the juveniles are the lack of sex education, there unawareness about these facts can led to crimes like cyber pornography, passing of sexually explicit materials online etc. Juvenile's have an immature mind which can also led them to trust any other person very amicably, which can also misguide them in the field of using computers and can led them to cause cyber crime in the virtual world.

While, concluding this article, we can say that there can be numerous factors which can lead to the cyber delinquency sometimes knowingly and sometimes unknowingly. But the most worrying factor is that the young people get easily involved in this world as they may see it being risk free. Community, parents are the most important primary group which can either led to cyber delinquency or stop them from doing the same.

\section{REFERENCES}

1. Stamenkovic, Marko, 2012, "In full view: Cyber suicide, Self and Public show case of death" (for real). 5 (12); 73 101.

2. A brief study on Cyber Crime and Cyber Law's of India Animesh Sarmah, Roshmi Sarmah, Amlan Jyoti Baruah,

3. JUVENILE DELINQUENCY IN INDIA- LATEST TRENDS AND ENTAILING AMENDMENTS IN JUVENILE JUSTICE ACT Deepshikha Agarwal

4. Dr. Bhagyashree Deshpande and Anuradha Girme, "Research Methods Made Simple", International Journal of Innovative Technology and Exploring Engineering, 2019.

5. Dr.Ujwala Bendale and Vidya Dhere, "Right of Aged Persons to Live with Dignity: A Socio-Legal Perspective", International Journal of Innovative Technology and Exploring Engineering, 2019.

6. Sukrut Deo and Dr. Sapna Deo, "Cyber squatting: Threat to Domain Name", International Journal of Innovative Technology and Exploring Engineering, 2019.

7. Ms. Vidya Dhere and Dr.Ujwala Bendale, "Impact of Smart City on Social Relations", International Journal of Innovative Technology and Exploring Engineering, 2019.

8. Anuradha Girme and Dr. Bhagyashree Deshpande, "The Life Line of Human Beings - Right to Potable Water", International Journal of Recent Technology and Engineering, 2019.

9. Sukrut Deo and Dr. Sapna Deo, "Domain Name and its Protection in India", International Journal of Recent Technology and Engineering, 2019.

10. Sarda, M., Deshpande, B., Dharm, J., Dhere, V., Different aspects of environmental laws , International Journal of Recent Technology and Engineering, 2019

11. Sarda, M., Deshpande, B., Deo, S., Karanjkar, A comparative study on Maslow's theory and Indian Ashrama system, International Journal of Innovative Technology and Exploring Engineering ,2018

12. Sarda, M., Deshpande, B., Shringarpure, S., Smart city Use of technology and the needed labor reforms, International Journal of Innovative Technology and Exploring Engineering, 2018

13. Anwesha Pathak and A. Mishra, "Human Trafficking In India", Journal of International Pharmaceutical Research, 2019

14. Rashmi Dubey and Ujjwala Sakhalkar, "A Critical Analysis of Rising Intolerance and Growing Polarisation: Lynching", Journal of International Pharmaceutical Research, 2019

15. Jayashree Khandare and Anisa Shaikh, "When life becomes death: a stifling story of air pollution", Journal of International Pharmaceutical Research, 2019 